from both glasses after the original test has been carried out and looking at the wet preparation of the deposits under the $\times 40$ objective lens of a microscope. This has been helpful in elucidating patients with asymptomatic urinary schistosomiasis.

Over a four year period (1991-94), we undertook 840 such "modified" two glass urine tests. Of this, $52(6 \%)$ showed Schistosoma haematobium, the treatment of which led to a resolution of the urethritis. The patients involved, who were adults, did not have a history of terminal haematuria which would have alerted a clinician to the probable diagnosis of urinary schistosomiasis. A history of contact with water and past haematuria which abated spontaneously or after local herbal preparations were taken, was elicited on re-questioning. Two-thirds of these patients resided in a known schistosomiasis endemic area of the country. We would have missed this diagnosis if the modified test had not been carried out.

It is suggested that in patients hailing from schistosomiasis endemic areas reporting with a suspected urethritis for which no cause has been found, the "Kumasi modified" two glass test could be useful in elucidating the presence or otherwise of $S$ haematobium, whose treatment will prevent the development of complicated schistosomiasis.

YAW ADU-SARKODIE Komfo Anokye Teaching Hospital PO Box 1934 Kumasi

1 Mitchell SA, Shukla SR, Thin RN. Aetiology of non gonococcal urethritis: a possible relation to other infections. Int $f$ STD AIDS 1990;1:429-31.

2 Anonymous. Urethral discharge: diagnostic. In: Adler M W ed. $A B C$ of Sexually Transmitted diseases. 2nd ed. London BMA. 1990.

Accepted for publication 9 July 1996.

\section{Reasons for condom failure among chlamydia infected patients attending a department of genitourinary medicine in Copenhagen}

Safer sex with consistent and correct use of condoms in the case of sexual intercourse outside of longstanding, mutually monogamous relationships has been, and still is, the main message of public educational campaigns for the prevention of HIV infection in Denmark. In recent years several reports have indicated an increased use of condoms. ${ }^{1-3}$ However, as many as $40 \%$ of young adolescents do not use barrier contraception at first sexual intercourse, ${ }^{1}$ and a recent study showed that $38 \%$ of women attending a genitourinary medicine (GUM) clinic in London never or only occasionally used condoms. ${ }^{4}$ When engaged in vaginal intercourse with non-regular partners only $44 \%$ always used condoms. ${ }^{4}$

If we want to optimise our public campaigns recommending the use of condoms in case of casual sexual intercourse, it is necessary to expose in depth the reasons for inconsistent or incorrect use of condoms. In order to evaluate this aspect we asked 49 consecu- tive chlamydia positive heterosexual patients attending the department of GUM at Bispebjerg Hospital to complete an anonymous standardised questionnaire. One woman did not answer the questionnaire and was therefore excluded from analysis, giving a completion rate of $98 \%$. Of the 48 included patients, 24 were males and 24 were females. Each patient was asked to specify which of the statements in 20 questions fits with their attitude to or experience with condoms. At least one and maximally three of the items given in the table could be ticked off as correct by the patient.

\section{Barriers to use}

Decreased pleasure of sex, irritation due to interruption of the sexual act or unromantic feelings played a role for 24 patients $(50 \%)$ who chose not to use condoms. These emotional reasons were found with the same prevalence among males and females (table). Only two male patients had significant erection problems when using condoms.

\section{Sex with regular partner}

Sexual relationship with a steady partner was a major reason for having unsafe sex in 5 patients $(10 \%)$. Especially female patients relied on this information as a valid indicator for choosing not to use condoms (table). A male patient reported that he knew his sexual partners sufficiently well as the reason for having sex without a condom.

\section{Alcohol intake}

A total of 12 patients (25\%) mentioned that alcohol with sex were an essential factor for not using condoms. There seems to be no major difference between males and females in their attitude to drinking alcohol in relation to sexual intercourse (table).

\section{Self-efficacy}

Low self-esteem was a contributing factor in 11 patients (23\%), all being females. They found that items $1-5$ in the table had major impact on their decision of not using condoms.

\section{Condom not available}

Eight patients (17\%) stated that lack of a condom in the actual risk situation was the reason for having practised unsafe sex.

\section{Using other methods of contraception}

Seven patients (15\%) had not used condoms as other forms of contraceptive methods were in practise simultaneously (table).

\section{Intellectual insufficiency}

Not using a condom (although available), lack of care or considering not being in risk of contracting a sexually transmitted disease were primarily mentioned by male patients. Nine of eleven patients that responded positively to statements $6-8$ in the table were males. In addition stupidity and slovenliness were noticed by a female and a male patient, respectively. 
Attitudes concerning use of condoms among 24 males and 24 females with a recent diagnosis of chlamydia

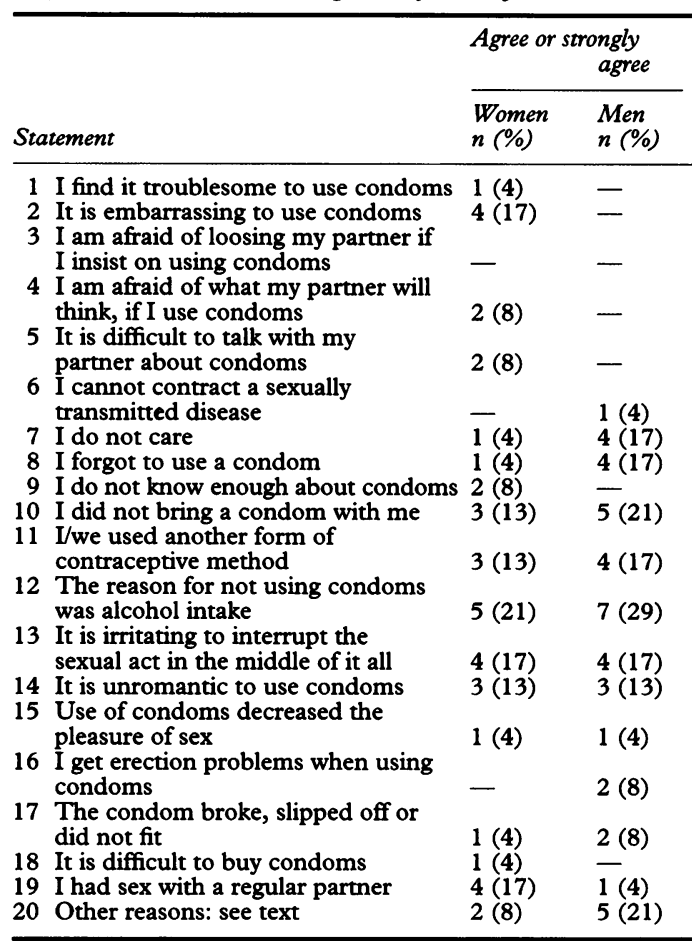

\section{Practical problems}

Only one female found that it was difficult to buy condoms, whereas three patients said that aspects concerning use of condoms (item 17, table) could have influenced their risk of contracting chlamydia.
Other reasons

One male patient expressed a general negative attitude to the use of condoms. Two males mentioned that "it went too fast" and a female deliberately "decided to take a chance".

Summarising our data, it seems that several factors needed to be considered in order to increase the use of condoms among chlamydia infected patients attending a GUM clinic: increased efforts to use condoms in cases of casual sexual relationship, addressing the perception that condoms can interfere with sexual pleasure, emphasising the dangers of using alcohol with sex, assisting women in increasing self-efficacy and encouraging men to take greater responsibility for wearing condoms, stressing that sex with steady partners usually is unsafe sex and finally that condoms always should be used simultaneously with other nonbarrier contraceptive methods.

HANNE SØRENSEN AASE HØRNER VENEGAS CARSTEN SAND PETERSEN Department of Dermato-venereology, Bispebjerg Hospital, University of Copenhagen

Correspondence to: Hanne Sørensen.

1 Wielandt HB. Have the AIDS campaigns changed the pattern of contraceptive usage among adolescents? Acto tern of contraceptive usage among

2 DeBuono BA, Zinner SH, Daamen M, McCormack WM. Sexual behaviour of college women in 1975,1986 and Sexual behaviour of college women
1989 . $N$ Engl $₹ \mathrm{M}$ ed 1990;322:821-5.

3 Olivarius F de Fine, Worm AM, Petersen CS, Kroon S, Lynge E. Sexual behaviour of women attending an innercity STD clinic before and after a general campaign for safer sex in Denmark. Genitourin Med 1992;68:296-9.

4 Sonnex C, Hart GJ, Williams P, Adler MW. Condom us by heterosexuals attending a department of GUM: attitudes and behaviour in the light of HIV infection Genitourin Med 1989;65:248-51. 